Article

\title{
Microstructural and In Situ Lorentz TEM Domain Characterization of As-Quenched and $\gamma^{\prime}$-Precipitated $\mathrm{Co}_{49} \mathrm{Ni}_{30} \mathrm{Ga}_{21}$ Monocrystal
}

\author{
Andrzej M. Zak ${ }^{1, *(\mathbb{D})}$ and Wlodzimierz Dudzinski ${ }^{2}$ \\ 1 Electron Microscopy Laboratory, Faculty of Mechanical Engineering, Wroclaw University of Science and \\ Technology, Wybrzeże Wyspianskiego 27, 50370 Wrocław, Poland \\ 2 Faculty of Technology and Engineering, Wroclaw University of Science and Technology, Armii Krajowej 78, \\ 58302 Wałbrzych, Poland; wlodzimierz.dudzinski@pwr.edu.pl \\ * Correspondence: andrzej.zak@pwr.edu.pl
}

Received: 20 January 2020; Accepted: 22 February 2020; Published: 28 February 2020

check for updates

\begin{abstract}
The article concerns the rarely described magnetic domain structure of Heusler alloys in the case of a single crystal [100]-oriented Co-Ni-Ga alloy. The structure of the magnetic domains of the alloy was compared in two states: in the quenched and additionally aged state. Ageing led to precipitation of the spherical phase $\gamma^{\prime}$ nanoparticles (Co-rich, FCC lattice with a $=0.359 \mathrm{~nm}$ ). Lorentz transmission electron microscopy observation methods combined with cooling and in situ heating of the sample in the transmission electron microscope in the temperature range from $140 \mathrm{~K}$ to $300 \mathrm{~K}$ were combined to observe the magnetic domain structure. Significant differences in the dimensions and morphology of magnetic domain boundaries have been demonstrated. The quenched sample showed no change in stripe domain structure when the aged sample showed significant development of branching magnetic structures. This may be due to a change in the chemical composition of the matrix resulting from a decrease in cobalt and nickel content at the expense of precipitations.
\end{abstract}

Keywords: magnetic shape memory alloy; MSMA; CoNiGa; Lorentz TEM; Fresnel TEM; magnetic domain; domain walls

\section{Introduction}

Microstructure observations of magnetic shape memory alloys (MSMA) have always been a way to explain magnetic and physical phenomena [1]. However, before we discuss the magnetic structure of MSMA, we should briefly describe all the phases that may exist in scientifically popular alloys. The exact appearance of the binary graph of the Ni-Ga binary system has been investigated from the 1940s [2] and is still the subject of considerations [3]. The Co-Ni binary system comprises one phase: a substitutional solid solution with unlimited solubility. The Co-Ni binary alloys, which contain less than $30 \%$ of $\mathrm{Ni}$, can undergo martensitic transformation close to room temperatures [4]. In the ternary Co-Ni-Ga system, there are three elements, which differ significantly in the shape of the crystal lattice. This causes that there are many intermetallic phases in the system. At room temperature, most of the tested Co-Ni-Ga alloys exhibit a stable one-phase or two-phase structure. The phase equilibria between the B2, $\gamma$, and $\gamma^{\prime}$ phases in the Co-Ni-Ga system and phase structures are rather similar to those in Co-Ni-Al because Al and Ga belong to the same group in the periodic table [5]. The B2 type, body-centred cubic austenite phase, with a lattice parameter $\mathrm{a}=0.287 \mathrm{~nm}$, was determined at room temperature [6,7]. The lattice parameters of the low-temperature martensite phase have been determined to be the $\mathrm{L} 1_{0}$ type tetragonal lattice with parameters $\mathrm{a}=0.391 \mathrm{~nm}$ and $\mathrm{c}=0.315 \mathrm{~nm}$ [8]. The layered martensitic structures, which were encountered frequently in Ni-Mn-Ga [9] and Ni-Fe-Ga alloys, have not been found in the Co-Ni-Ga system [5]. In addition, for the Co-Ni-Ga alloy, there was 
no tendency to additionally order the crystal lattice at high temperatures, as noted for the Ni-Mn-Ga alloy [10]. Most sources state that both the macroscopic and nanometric crystals of the $\gamma^{\prime}$ phase have a face-centred cubic lattice with a parameter $\mathrm{a}=0.359 \mathrm{~nm}$ [11-13]. One of the teams, using the X-ray diffraction method, measured that the $\gamma$ phase has a cubic structure with a parameter a $=0.408 \mathrm{~nm}$ [14]. It is common in the literature to describe the electron diffraction patterns characteristic of $\gamma$ as the diffraction from the $\gamma^{\prime}$ phase [15]. Precipitation of the $\gamma^{\prime}$ phase causes a decrease in Ni concentration in the B2 phase matrix [5].

Soon after the discovery of the interesting properties of the one-phase Co-Ni-Ga alloy, it was discovered that it may be subjected to quenching and ageing in order to separate fine-dispersed precipitates of $\gamma^{\prime}$ phase from the austenite matrix. The particles gave characteristic, additional diffraction reflections and a clear image in the bright- and dark-field TEM observations [8]. Ageing treatments at $620 \mathrm{~K}$ performed in $\mathrm{Co}_{49} \mathrm{Ni}_{21} \mathrm{Ga}_{30}$ single crystals have been found to generate dense dispersions of precipitates. These particles have a strong influence on the martensitic transformation, decreasing the overall transformation temperatures [16]. This is justified by the change in the chemical composition of the matrix: the $\mathrm{B} 2$ phase. It has also been proven that different temperatures and ageing times lead to separation and different shapes, from spherical to needle-like [17]. Variations in the size and morphology of precipitates have also been achieved by ageing under the additional effect of compressive stress [15]. A similar effect of precipitating was also observed for the Co-Ni-Al [18] and Fe-Ni-Co-Al-Ta [19] alloys.

In situ TEM heating experiments for the Co-Ni-Ga alloy were only performed for the $\mathrm{Co}_{46} \mathrm{Ni}_{27} \mathrm{Ga}_{27}$ polycrystalline alloy [13]. The results confirmed a crystallographic relation between the austenitic, martensitic and $\gamma$ phase: (111) L1 $\|$ (110) B2 $\|(111) \gamma$. It has been shown that the martensite structure in Co-Ni-Ga alloys can present the multi-variant structure with a high amount of twinning [5]. From the selected area diffraction pattern there is a possibility to confirm the theoretically probable twinning habitus plane as (111) [11]. The Co-Ni-Ga quenched alloy exhibits a characteristic tweed pattern in the austenitic B2 phase [20]. In [21], the authors connected the tweed pattern with diffuse streaks along the $\{110\}$ plane's family directions. The authors of [22] demonstrated observations of tweed with a high-resolution Lorentz transmission electron microscopy (TEM) microscope. It proved the dual, magnetic, and elastic nature of the tweed pattern. The phenomenon of tweed structure, however, has still not been fully explained. In the Ni-Fe-Ga system, it was observed that the presence of a tweed pattern is associated with the presence of additional, longitudinal electron diffraction spots [23]. TEM observations, combined with differential scanning calorimetry (DSC) measurements, allowed the tweed pattern to be assigned with the premartensitic transformation phenomena [24].

Studies on the domain structure of Co-Ni-Ga alloys can be divided due to observation methods: magnetic force microscopy (MFM), and light or electron microscopy. Light microscopy is still the most frequently used technique that allows many phenomena occurring in shape memory alloys to be described [25]. Observations of the $\mathrm{Co}_{48} \mathrm{Ni}_{22} \mathrm{Ga}_{30}$ single crystal using polarized light microscopy, called Kerr microscopy, showed that in a martensitic state each martensitic plane is divided into $180^{\circ}$ magnetic domains and the twin boundaries are $90^{\circ}$ magnetic domain walls of the Bloch type [26]. The $180^{\circ}$ magnetic domains are continuous within the crystal grains and intersect the planar mutually parallel walls of the martensitic domains.

In situ observations during the interaction with the magnetic field allowed it to be stated that after the magnetization of the alloy, the new family of magnetic domains exhibits similar structural features as the original ones, but with the orientation characteristic of the applied magnetic field [27]. MFM gives the opportunity to observe structures on similar scales as TEM and were used to describe magnetic anisotropy [28-31]. MFM method in $\mathrm{Co}_{45} \mathrm{Ni}_{25} \mathrm{Ga}_{30}$ alloy allowed to observe high magnetic anisotropy of the B2 phase [28]. However, the impact of crystal orientation on the domain structure of the alloy was not considered, so it is difficult to accurately refer to these results. Direct magnetic measurements determined that the $\{100\}$ planes of the $\mathrm{B} 2$ phase coincide with the direction of easy magnetization of $\mathrm{Co}_{47.5} \mathrm{Ni}_{22.5} \mathrm{Ga}_{30.0}$ single crystals [32]. 
Changes in the domain structure of magnetic shape memory materials as a function of temperature were not a frequent subject of research. The existence of magnetic domain wall contrast in the Co-Ni-Al alloy, whereas using the Lorentz TEM indicated that the sample is ferromagnetic at this temperature [18]. The alloy changed its magnetic structure at lower temperatures-magnetic domains in $219 \mathrm{~K}$ were $4 \mu \mathrm{m}$ wide, and in $105 \mathrm{~K}$ were only $200 \mathrm{~nm}$ wide. The authors of [21] observed the domain structure of the $\mathrm{Co}_{48} \mathrm{Ni}_{22} \mathrm{Ga}_{30}$ alloy in a quenched state, but only in the low-temperature martensite phase. They noticed parallel domains approximately $300 \mathrm{~nm}$ wide. A much more random shape of the magnetic domains was observed for the Ni-Mn-Ga alloy. At the same time, domain repeatability was recorded during subsequent in situ magnetic transformation cycles [33].

This work is an extension of the static domain structure observation published earlier [34]. The work [34] incorrectly uses the assumption that the Foucault method was used to observe the domain structure. Instead, it was observed using a specially developed method of revealing magnetic domains by means of ion polishing [35]. Due to the fact that the ion polishing method permanently and irreversibly reveals the magnetic structure, in this work, the Fresnel observation methods were used. The important value of this work is to examine the material in two different heat treatment states, as well as at temperatures in the range from $130 \mathrm{~K}$ to $300 \mathrm{~K}$.

\section{Materials and Methods}

The $\mathrm{Co}_{49} \mathrm{Ni}_{21} \mathrm{Ga}_{30}$ alloy of nominal weight composition was prepared from powders of $\mathrm{Co}, \mathrm{Ni}$, and Ga by melting in a high-frequency induction furnace under high vacuum conditions. The $\mathrm{Co}_{49} \mathrm{Ni}_{21} \mathrm{Ga}_{30}$ alloy [001] oriented monocrystal was obtained using the modified Bridgman method, as in work [17, 36-38]. The crystal growing was performed on a modified REDMET-1 unit courtesy of Prof. Yuri Chumlaykov in Tomsk State University.

For maximum chemical homogeneity of single crystals, samples of $\mathrm{Co}_{49} \mathrm{Ni}_{21} \mathrm{Ga}_{30}$ were then annealed at $1443 \mathrm{~K}$ for $8 \mathrm{~h}$ in a quartz tube in a helium atmosphere, followed by quenching in water. It made the material into a metastable one-phase state. To obtain the presence of spherical, nanometric precipitates, some of the samples underwent an additional process of ageing at $603 \mathrm{~K}$ for $15 \mathrm{~min}$.

The samples for TEM observations were prepared using mechanical thinning down to $100 \mu \mathrm{m}$, followed by electrolytic polishing using Struers Tenupol 5 and reagent containing 10\% perchloric acid in butoxyethanol.

The microscope used in most of the work was a Hitachi H-800, equipped with a tungsten filament and an Olympus Quemesa camera. The operating voltage of the device was $150 \mathrm{kV}$. TEM observations of the magnetic structure were performed with the Fresnel method $[39,40]$ using "free lens mode", which allows the operator to manually set the value of each current in the electron lenses. It allows the sample image to be focused using the first intermediate lens instead of the switched-off objective lens. Due to the stepping characteristics of the intermediate lens focusing, it was not always possible to determine the ideal in-focus position. In this case, the image with the weakest contrast coming from the magnetic structures was used for the in-focus image. Due to the fact that the only values controlled were the currents flowing through the lenses and sufficient information about the construction of the optical system was not provided, in most pictures we cannot specify the defocus value. The maximum magnetic field in the pole piece gap, with the objective lens switched off (residual magnetization of objective pole-piece), was measured using an Asonik SMS 102 hall probe magnetometer and amounted to $6 \mathrm{mT}$. In situ cooling experiments were performed using a side-entry cooling holder-a modified Hitachi H-5001C, with operating temperatures of 130 300 K, the T-type thermocouple and digital indication of temperature. The holder ensures an unchangeable heating/cooling rate, which is presented in Figure 1. The cooling rate determined for the holder was $\sim 20 \mathrm{~K} / \mathrm{min}$, and for heating was from 2 to $4 \mathrm{~K} / \mathrm{min}$. The device allows continuous and stable observations only at the temperature range of $130 \mathrm{~K}$ or $300 \mathrm{~K}$. Fresnel imaging was performed during the continuous heating process, so the image sets at a given temperature were made with a discrepancy of $\sim 4 \mathrm{~K}$. 


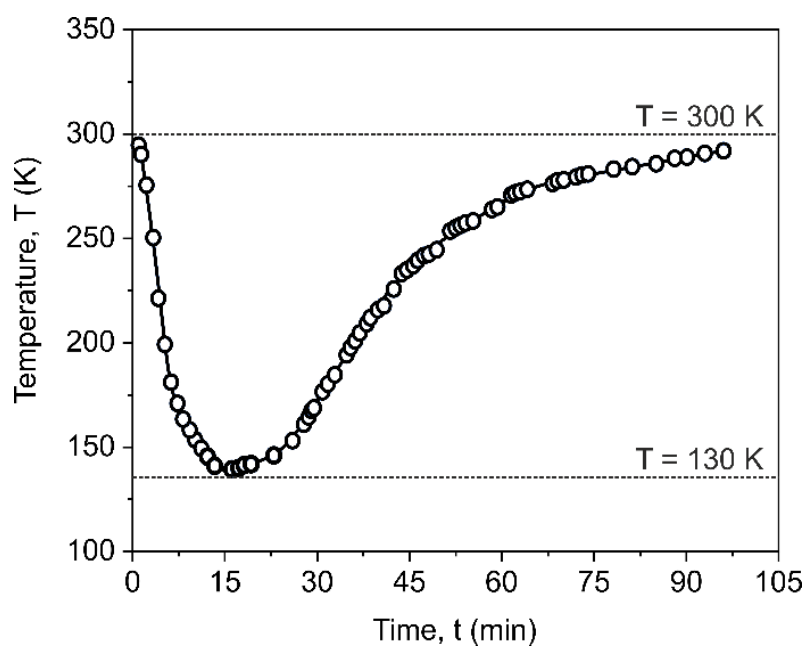

Figure 1. Temperature/time graph for continuous cooling or heating in the Hitachi H-5001C cooling holder.

Selected area electron diffraction (SAED) patterns were calculated using DYFR software, originally created by Prof. Włodzimierz Dudziński in the Institute of Material Science and Mechanical Engineering at Wroclaw University of Science and Technology. The software has been used in a number of previous publications [41-43]. Calculations were taken by comparing the results of the diffractogram measurements with the database of all available patterns for probable phases.

Additional, static observation of the magnetic microstructure of the quenched $\mathrm{Co}_{49} \mathrm{Ni}_{21} \mathrm{Ga}_{30}$ sample was performed on a high-resolution JEOL JEM-F200 CR transmission microscope, using accelerating voltage of $200 \mathrm{kV}$. The Lorentz mode was available using Low-Mag function, with an objective lens turned off and objective mini-lens turned on. The residual magnetization of the objective pole-piece was not measured, so these results will only be considered as the direction of the next study.

\section{Results}

For both types of samples, after preliminary room temperature observations, a series of in situ experiments were performed in the TEM microscope column. Observations were made successively during continuous cooling of the sample to a temperature of $\sim 130 \mathrm{~K}$ while being held at this temperature for $1 \mathrm{~h}$, and then during continuous, slow heating to ambient temperature. The experiment was repeated for three samples, and in the further part of the work, the results obtained during many separate experiments were summarized. The monocrystalline nature of the material does not allow the transformation mechanism to be clearly illustrated. Observation of structural changes is also difficult due to the non-diffusion nature of the martensitic transformation and deformation of the thin sample during cooling and heating. Samples due to undergoing a transformation in a limited volume of thin foil cracked and did not allow observations during more than 2-3 cooling cycles.

\section{1. $\mathrm{Co}_{49} \mathrm{Ni}_{21} \mathrm{Ga}_{30}$ in the Quenched State}

The microstructure of the $\mathrm{Co}_{49} \mathrm{Ni}_{21} \mathrm{Ga}_{30}$ monocrystal in its quenched state was observed in the austenite phase [001] zone axis. Bright-field imaging mainly revealed the contrast associated with the presence of extinction contours. However, the course of the line indicates the presence of disturbances in the crystal structure, probably slip bands (Figure 2a). No dislocation or twinning structure was observed, which corresponds well with the heat treatment consisting of annealing for $8 \mathrm{~h}$ and quenching in water. Selected area diffraction patterns taken from non-tilted samples clearly show the presence of diffractions spots, which can be attributed to the B2 body-centred cubic lattice. The orientation of the crystal on the direction [001] was confirmed (Figure 2b). 

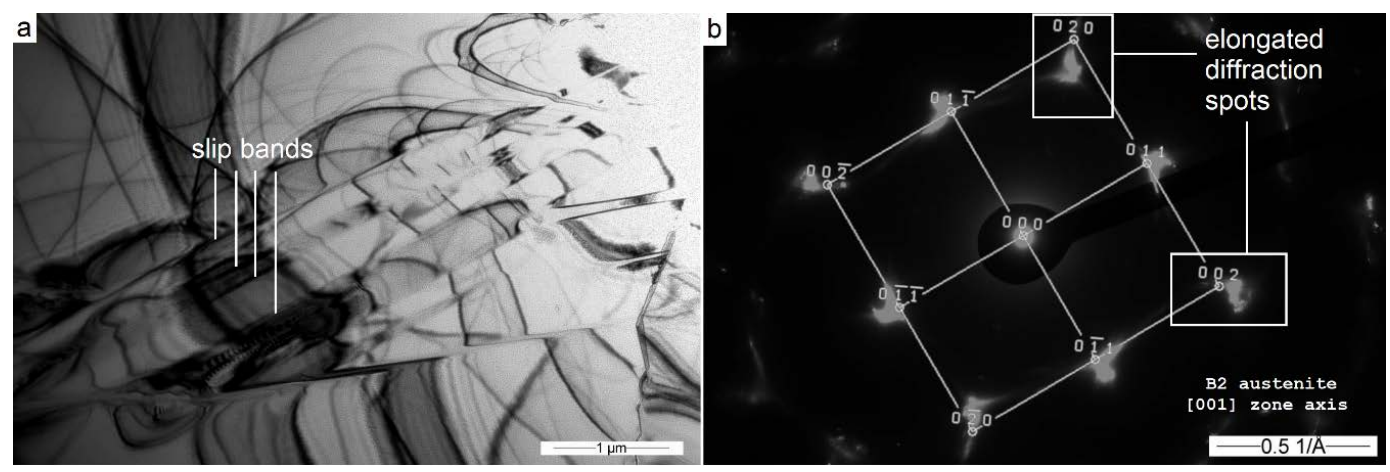

Figure 2. (a) Bright-field TEM image of the $\mathrm{Co}_{49} \mathrm{Ni}_{21} \mathrm{Ga}$ monocrystal in its quenched state and (b) an exemplary selected-area diffraction pattern.

Some diffractograms showed the elongation and blurring of some diffraction points to the inside or outside of the pattern (Figure 2b). According to literature data, a similar phenomenon may be justified in the case of hard magnetic materials with a noticeable domain structure [44-46]. The effects related to the magnetic structure of the sample and diffraction patterns have been described more detail in the paper [34]. Therefore, areas characterized by such diffraction patterns were subjected to Fresnel domain observations. An exemplary set of images in the under-focus, in-focus, and over-focus images are presented in Figure 3a. The under- and over-focus positions show the inverse contrast of vertical bands, which indicates the magnetic nature of the image.
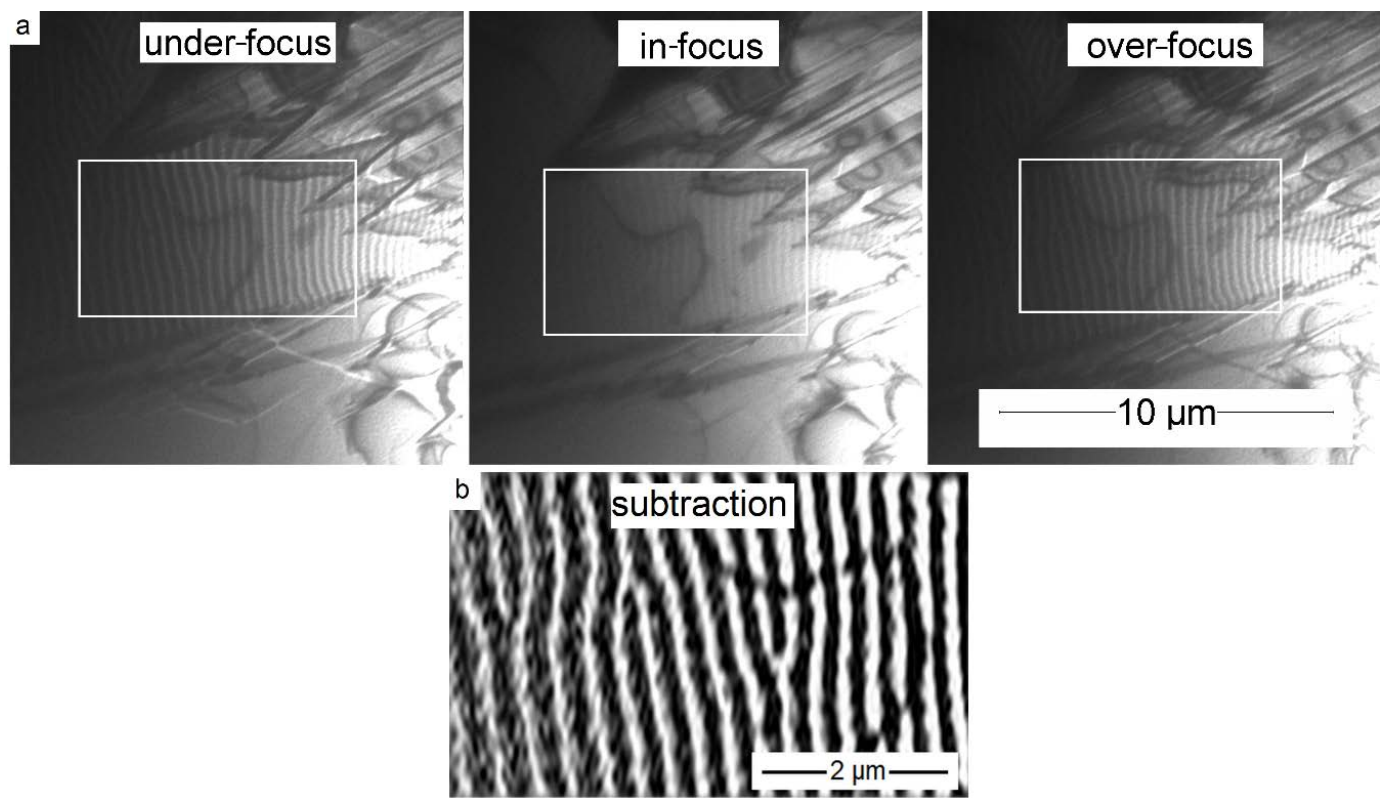

Figure 3. (a) Fresnel imaging of the $\mathrm{Co}_{4}{ }_{9} \mathrm{Ni}_{21} \mathrm{Ga}_{30}$ monocrystal in its quenched state at room temperature, the frame marks the place of the highest magnetic contrast, and (b) the subtraction of under- and over-focus images showing the approximate shape of the domain boundaries.

The magnetic domain structure of the $\mathrm{Co}_{49} \mathrm{Ni}_{21} \mathrm{Ga}_{30}$ monocrystal in its quenched state consists of $\sim 150 \mathrm{~nm}$ width parallel magnetic domains, arranged along the $\{001\}$ austenite phase planes. At the same time, micrometric, rhomboidal domains were observed, e.g., below the frame mark in Figure $3 a$. The coexistence of both types of domains (microscopic and highly periodic stripe domains) may be due to local heterogeneity in the magnetic properties of the material or local magnetic orientation along different planes of the $\{100\}$ family. Under- and over-focused images were subtracted from each other, which allowed better visualization of the contrast of magnetic domain boundaries (Figure 3b). 
Prior to the cooling process of one of the samples, it was rotated to receive the [011] zone axis of B2 austenite diffraction pattern at $293 \mathrm{~K}$ (Figure 4a). Additional diffraction points were visible, and identical to those observable in Figure 2b. Diffusion streaks were also observed, which may suggest the presence of a long-term ordering of the structure. Immediately after the transformation, the observed place bent, which at temperatures of 220 250 K made it difficult to obtain the correct diffraction pattern without changing the tilt angle (Figure $4 \mathrm{~b}, \mathrm{c}$ ). Only at $152 \mathrm{~K}$ and lower temperatures, it was possible to obtain the elementary cell associated with the $\mathrm{L} 1_{0}$ network of the martensitic phase in Figure $4 \mathrm{~d}$. The SAED taken from the martensite phase also reveal the presence of doubled spots, which can be caused by an internal strong magnetic field related to domain structure (marked in Figure $4 d$ ).
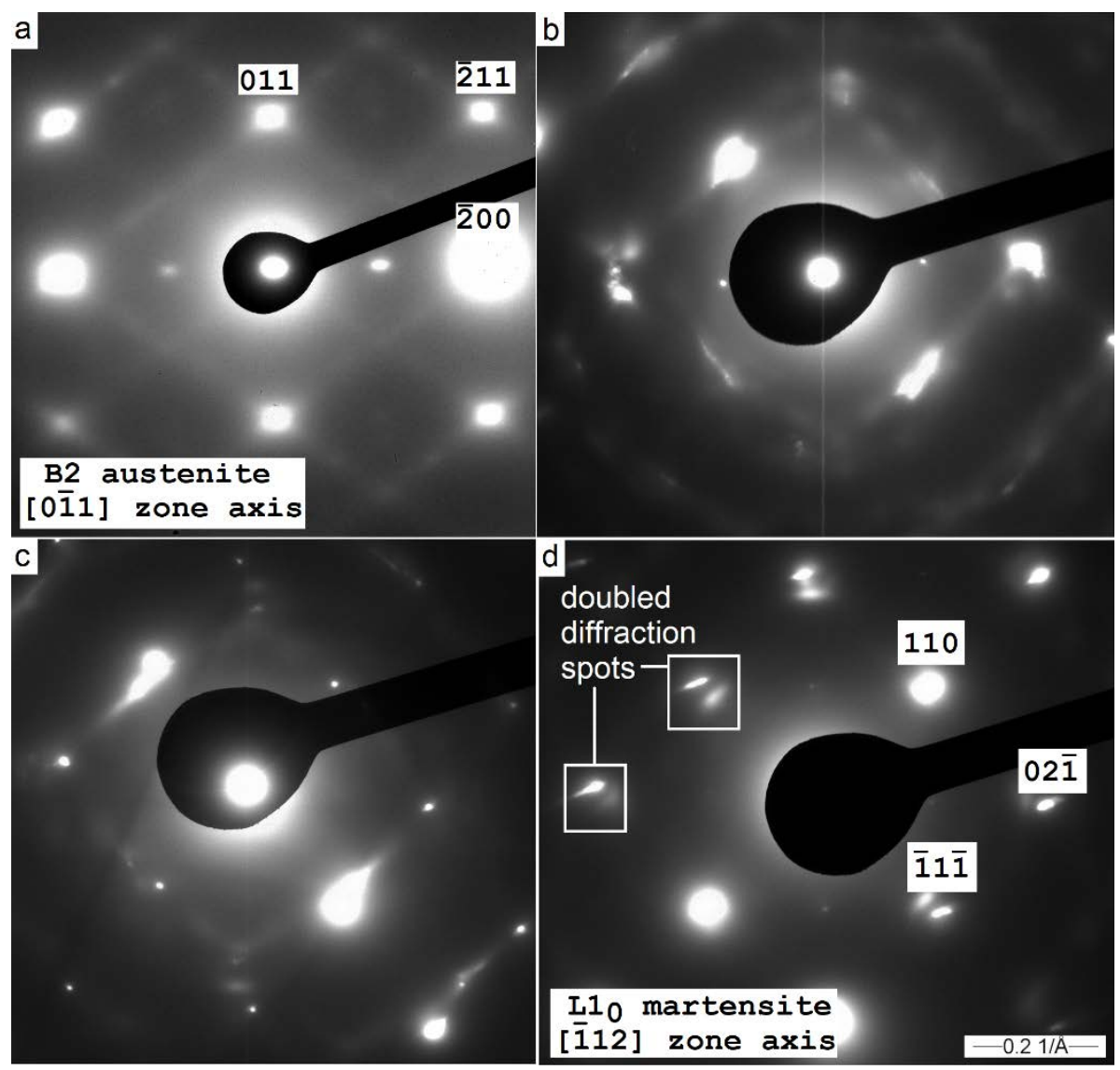

Figure 4. Selected area electron diffraction (SAED) pattern of the $\mathrm{Co}_{49} \mathrm{Ni}_{21} \mathrm{Ga}_{30}$ monocrystal in its quenched state during continuous in situ cooling at (a) $293 \mathrm{~K}$, (b) $249 \mathrm{~K}$, (c) $226 \mathrm{~K}$, and (d) $152 \mathrm{~K}$.

As similar effects on electron diffraction were observed for both the martensitic and austenitic phases, it was decided to compare the domain structure of the alloy in situ during the cooling process. Preliminary observations showed that the domain structure does not change significantly, and therefore Figure 5 shows the Fresnel images obtained at different temperatures. At lower temperatures, a significant change in the geometry of the thin film and the appearance of new extinction contours are clearly visible. However, in the magnetic domains marked with the frame, there were no significant changes and it still showed the presence of parallel domains of $\sim 150 \mathrm{~nm}$ in width. To objectively compare the contrast in the out of focus positions, the under-focus images were subtracted from the over-focus images. This process was performed for three sets of images. The first is the material before in situ cooling, the second is the sample cooled to $143 \mathrm{~K}$, and in the third, the material was heated back to ambient temperature. Analysis of the processed images indicated that during cooling and heating there may exist a slight reconstruction of the domain structure, but its accurate tracking 
requires a resolution of the order of single nanometers, which is impossible to obtain with the current configuration of the used device. However, in the entire range of temperatures, the tested visible domains have a parallel orientation and width from 100 to $200 \mathrm{~nm}$, without any significant changes (Figure 6).
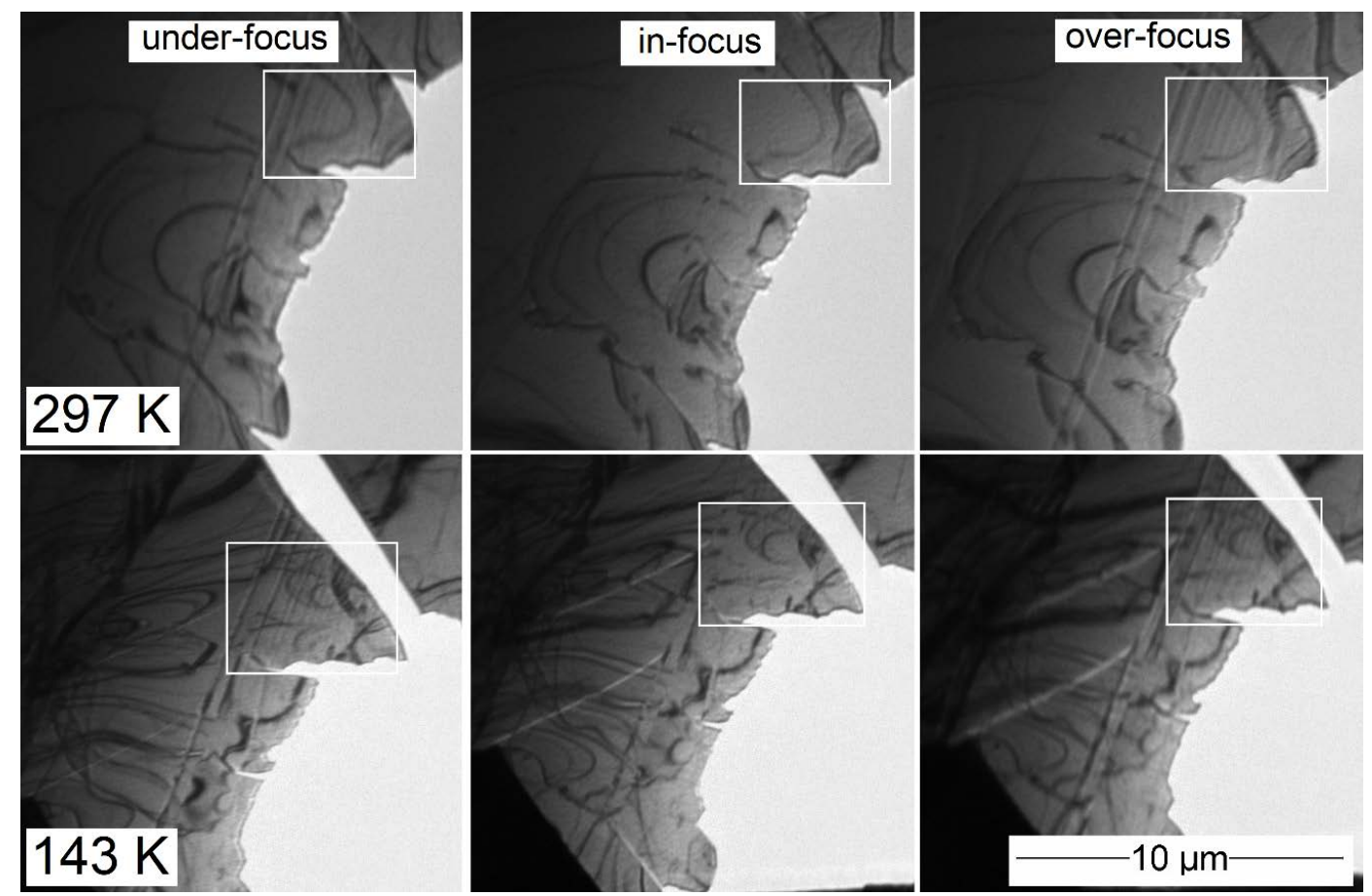

Figure 5. Fresnel imaging of the $\mathrm{Co}_{49} \mathrm{Ni}_{21} \mathrm{Ga}_{30}$ monocrystal in its quenched state at a temperature of $297 \mathrm{~K}$ and $143 \mathrm{~K}$, the frames mark the place of the highest magnetic contrast.

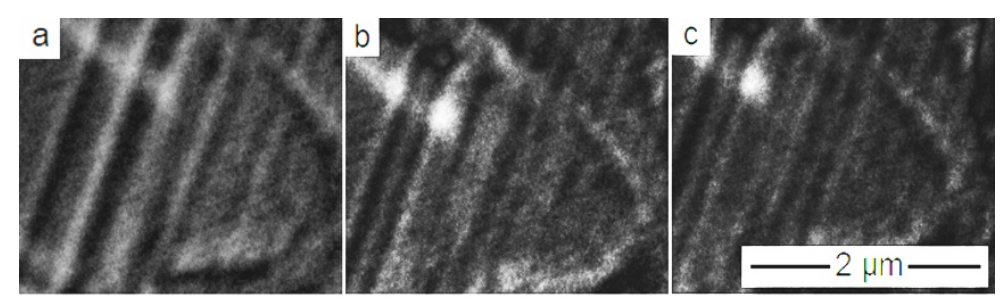

Figure 6. The subtraction of under-focus and over-focus images for the $\mathrm{Co}_{49} \mathrm{Ni}_{21} \mathrm{Ga}_{30}$ monocrystal in its quenched state, showing the effects associated with magnetic contrast: (a) $297 \mathrm{~K}$ before cooling, (b) $143 \mathrm{~K}$, and (c) $297 \mathrm{~K}$ after additional heating.

To check further observation perspectives using more resolved electron microscopes, additional observations were performed using a JEOL JEM-F200 CR microscope. The microscope has a standard, implemented solution for observation using Fresnel methods, so we managed to determine the defocus amount for under- and over-focus at $18 \mu \mathrm{m}$. In addition to confirming previous observations, internal magnetic subdomains of up to $12 \mathrm{~nm}$ have been observed (Figure 7). Determining the magnetic structure as a function of temperature using more advanced microscopes than the previously used Hitachi H-800 and comparing all results is a promising direction for further research. 

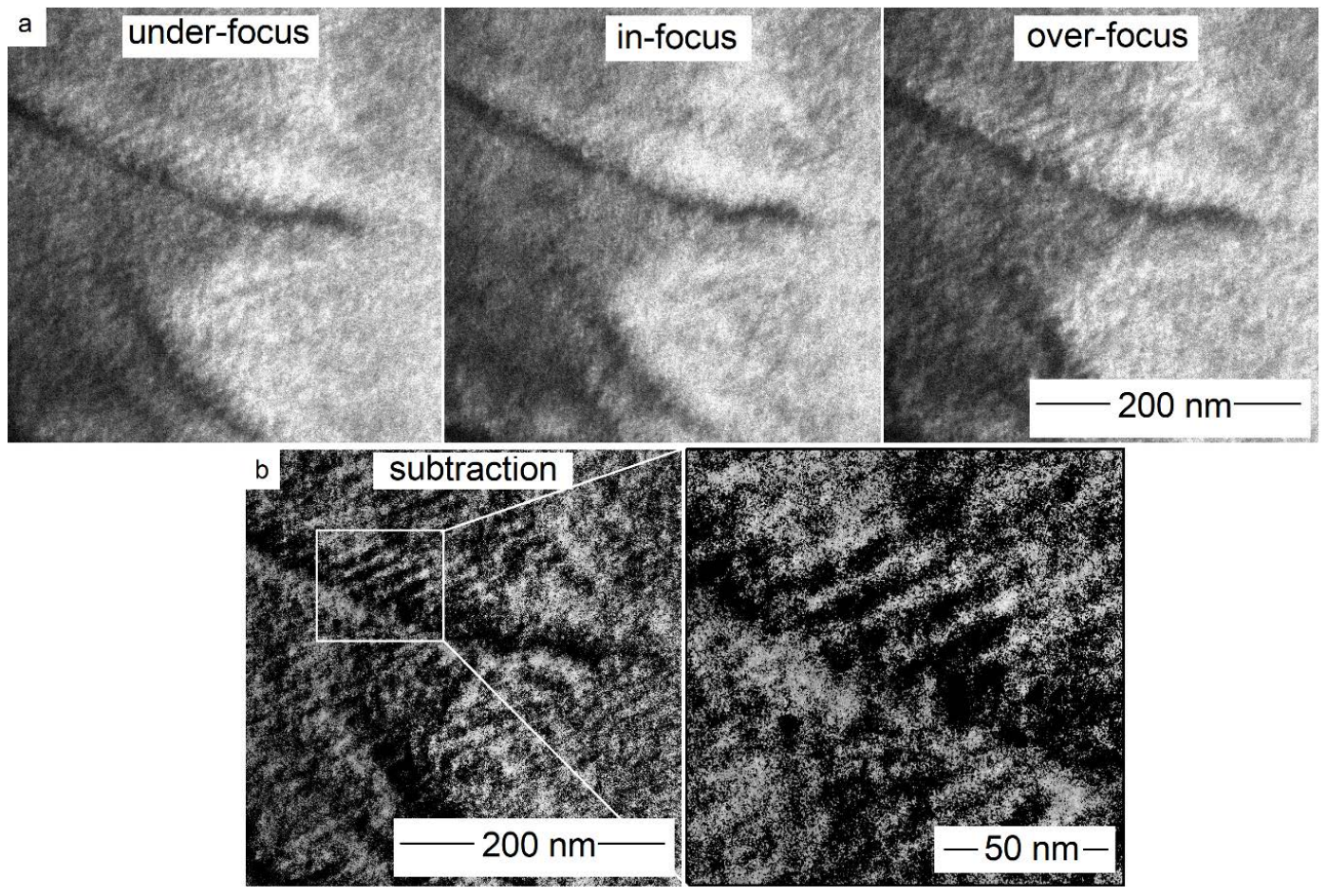

Figure 7. (a) Fresnel imaging of the $\mathrm{Co}_{49} \mathrm{Ni}_{21} \mathrm{Ga}_{30}$ monocrystal in its quenched state at a temperature of $297 \mathrm{~K}$ and (b) the subtraction of under-focus and over-focus images.

\section{2. $\mathrm{Co}_{49} \mathrm{Ni}_{21} \mathrm{Ga}_{30}$ in the Quenched and Aged State}

The microstructure of the $\mathrm{Co}_{49} \mathrm{Ni}_{21} \mathrm{Ga}_{30}$ monocrystal in its quenched and aged state was observed in the austenite phase [001] zone axis. Bright-field imaging revealed no extinction contours and the presence of a significant number of spherical $\gamma^{\prime}$ precipitates. A large number of precipitates made it very difficult to observe the structural effects associated with the B2 austenite matrix (Figure 8a,b). Locally, places with a lower density of precipitates can be observed along the planes (011) and (200) (Figure $8 b, c)$. Their presence may be related to the more difficult release of particles during ageing near defects such as slip or twins, which was observed previously in the quenched sample.

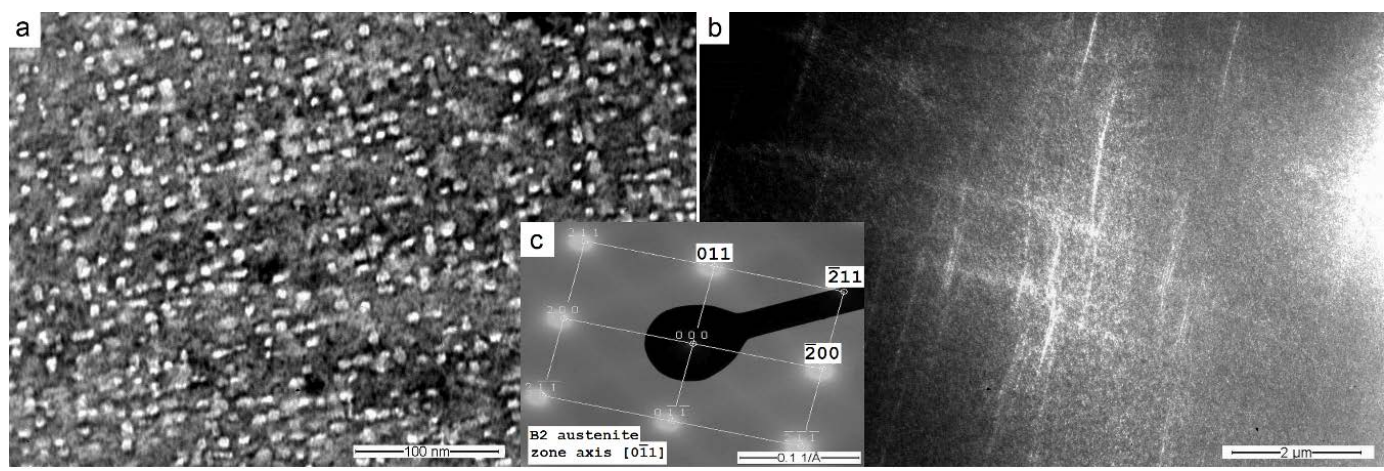

Figure 8. TEM (a) bright-field image of the austenitic $\mathrm{Co}_{49} \mathrm{Ni}_{21} \mathrm{Ga}_{30}$ monocrystal in its quenched and aged state with a significant number of regularly spaced nanoparticles and (b) areas of the smaller density of nanoparticles, (c) coinciding with the (011) and (200) planes on the SAED pattern.

Selected area diffraction patterns taken in the [011] zone axis of the austenitic matrix revealed the presence of additional, fuzzy and elongated diffraction spots (Figure 9a). The diffractogram taken in the [100] zone axis allowed additional spots to be recognized as $\gamma^{\prime}$ phase (Co-rich, FCC lattice with $\mathrm{a}=0.359 \mathrm{~nm}$ ) precipitations (Figure $9 \mathrm{~b}$ ). Unlike the quenched sample, it is not possible to obtain 
a diffraction pattern without the additional diffractions spots. The presence of $\gamma^{\prime}$ precipitations was finally confirmed by TEM observations in the dark field.

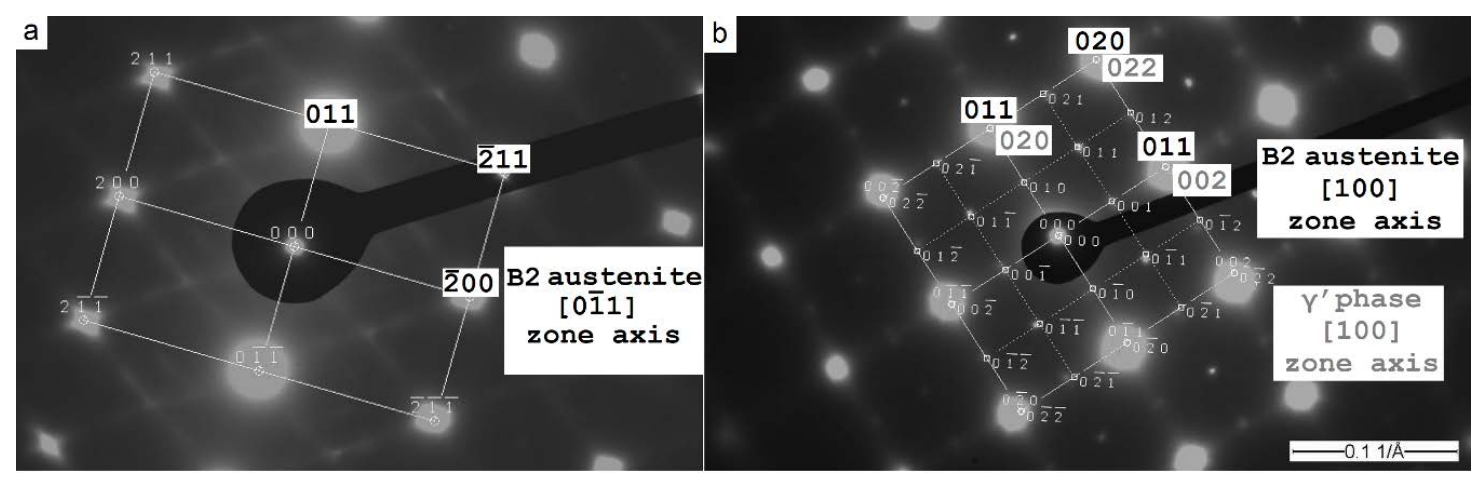

Figure 9. SAED patterns of the austenitic $\mathrm{Co}_{49} \mathrm{Ni}_{21} \mathrm{Ga}_{30}$ monocrystal in its quenched and aged state (a) showing fuzzy intersecting lines in the [011] zone axis and (b) extra diffraction spots recognized as the $\gamma^{\prime}$ phase in the [100] zone axis of the austenitic B2 matrix.

The images obtained using the bright- and dark-field methods were data allowing precise determination of the size and shapes of the nanoparticles using image processing software. After thresholding, using a semi-automatic script in the ImageJ program [47], each particle was approximated as an ellipse, and the transversal and conjugate diameter was measured. The particle size was expressed as the mean of these two diameters, and for the tested material it was $12.9 \mathrm{~nm}$ with a standard deviation of $2.4 \mathrm{~nm}$ (Figure 10).

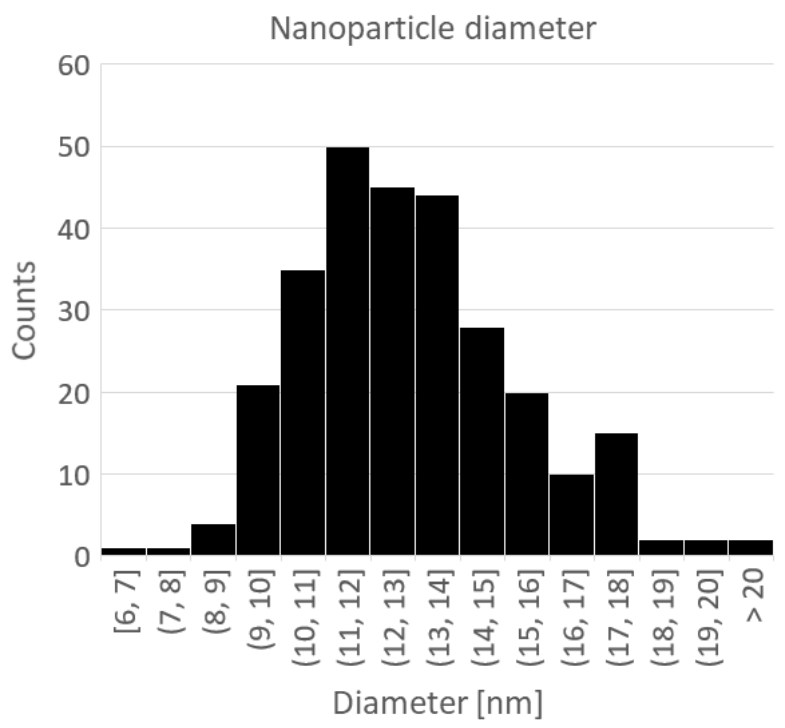

Figure 10. Histogram of the $\gamma^{\prime}$ phase precipitations diameter.

Fresnel imaging of the $\mathrm{Co}_{49} \mathrm{Ni}_{21} \mathrm{Ga}_{30}$ monocrystal in its quenched and aged state was performed with the objective lens switched off. An exemplary set of images in the under-focus, in-focus and over-focus positions is presented in Figure 11. The under- and over-focus positions show no contrast connected with the magnetic properties of the material at the temperature of $293 \mathrm{~K}$. 

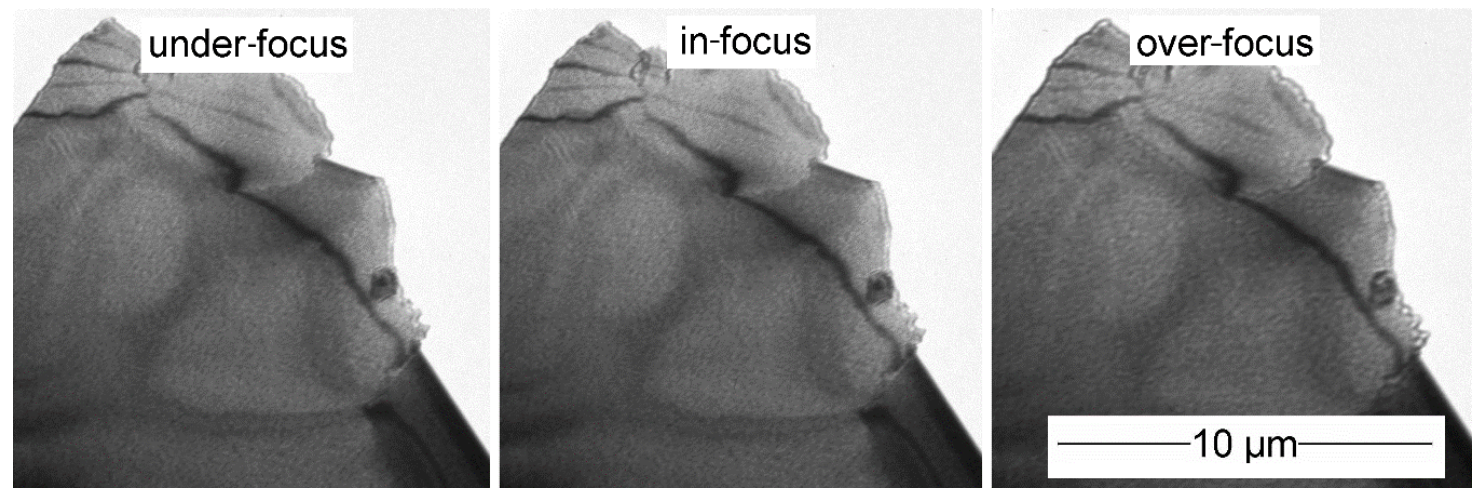

Figure 11. Fresnel imaging of the $\mathrm{Co}_{49} \mathrm{Ni}_{21} \mathrm{Ga}_{30}$ monocrystal in its quenched and aged state at $293 \mathrm{~K}$, showing no magnetic domain contrast regardless of the amount of defocus.

After the cooling sample down to $143 \mathrm{~K}$, observations of domain structure in the martensitic phase, in contrast to the austenite phase, showed the clear presence of magnetic domain contrast. The material contained irregularly arranged domains with a size of up to $1 \mu \mathrm{m}$ (Figure 12).

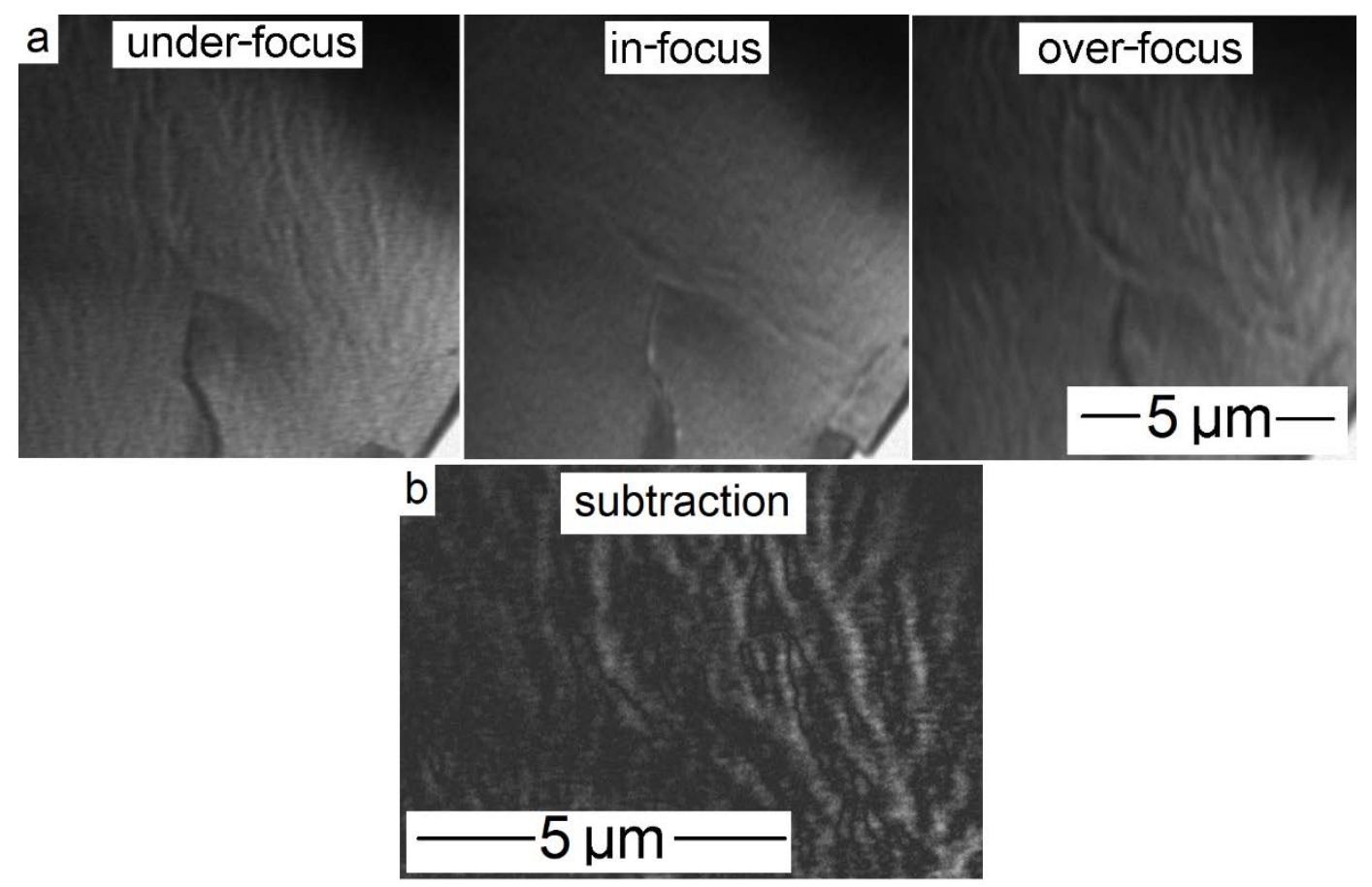

Figure 12. (a) Fresnel imaging of the $\mathrm{Co}_{49} \mathrm{Ni}_{21} \mathrm{Ga}_{30}$ monocrystal in its quenched and aged state at the temperature of $143 \mathrm{~K}$ and (b) the subtraction of under-focus and over-focus images.

A significant difference in the domain structure at ambient temperature and cooled state caused the need to observe the change in the domain structure as a function of temperature. A series of observations were made during the continuous heating of the sample. Due to the impossibility of stopping the heating process, observations at each temperature were made as quickly as possible. Therefore, temperature discrepancies during observations should not exceed $\pm 2 \mathrm{~K}$. For the best photo sets, subtractions of under- and over-focus images were taken to obtain a clean image of the domain boundaries. The development of the domain structure at temperatures of $273 \mathrm{~K}, 233 \mathrm{~K}$, and $143 \mathrm{~K}$ is presented in Figure 13. Magnetic domains are not visible at $273 \mathrm{~K}$, slightly revealed at $233 \mathrm{~K}$, and clearly noticeable at $143 \mathrm{~K}$. Extensive set of the Fresnel images was added in Appendix A. The difference between under- and over-focus images is not an image of domains, but only an image of one family of domain borders (white or black). This is a method that is convenient for revealing stripe domains, 
and faulty for domains of a different shape. The exact shape of the branching domains, arranged in pairs parallel to each other, can be seen in Appendix A.
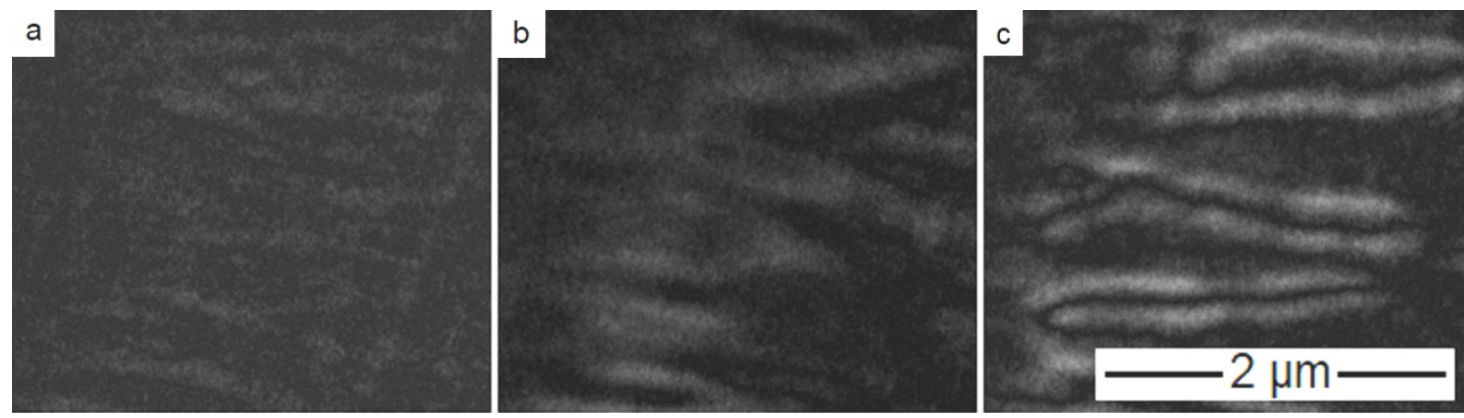

Figure 13. The subtraction of under-focus and over-focus images for the $\mathrm{Co}_{49} \mathrm{Ni}_{21} \mathrm{Ga}_{30}$ monocrystal in its quenched and aged state, showing the effects associated with magnetic contrast: (a) $273 \mathrm{~K}$, (b) $233 \mathrm{~K}$, and (c) $143 \mathrm{~K}$.

In situ bright-field microstructure analysis taken at $133 \mathrm{~K}$ reveals the presence of the structural defects. The dominating observable structure is internal twinning, both on a micro- (Figure 14a) and nanoscale (Figure 14b). There are no signs of internal slip, and twins often arrange themselves into multiscale structures: subgrains that have already been twinned can twin along different planes (Figure 14a, arrows).
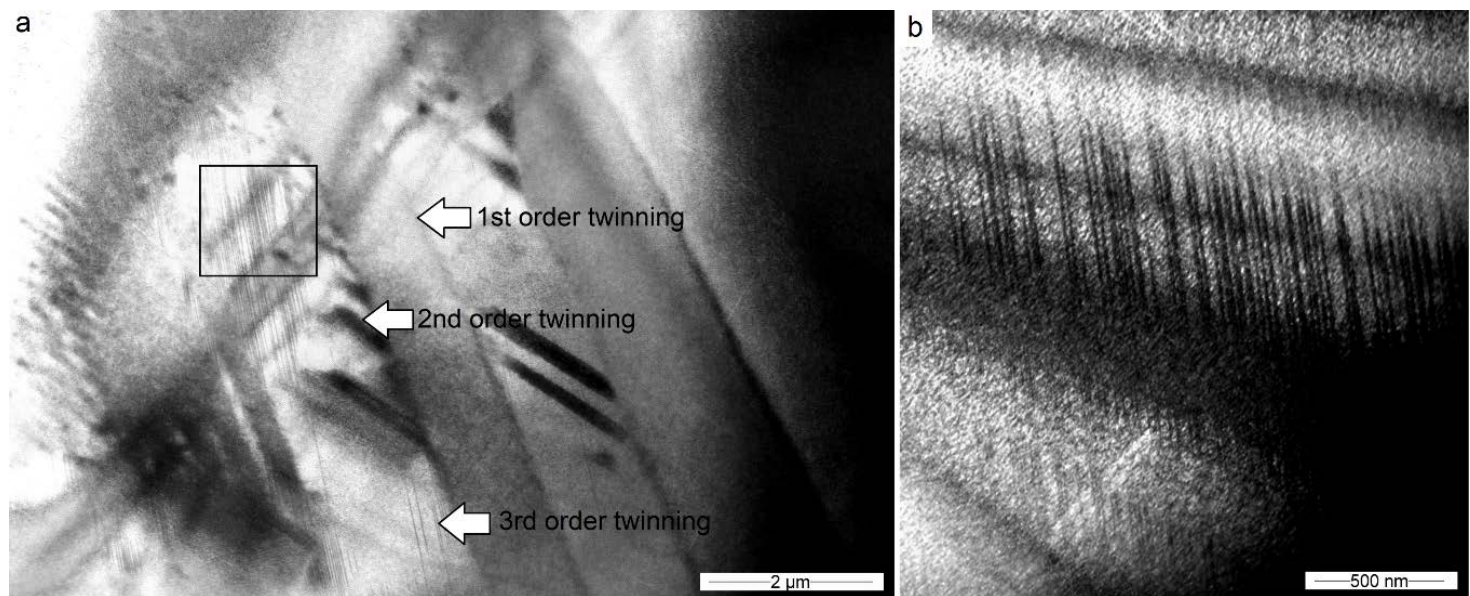

Figure 14. Multiscale twinning in the $\mathrm{Co}_{49} \mathrm{Ni}_{21} \mathrm{Ga}_{30}$ monocrystal in its quenched and aged state at the temperature of $133 \mathrm{~K}(\mathbf{a})$, magnified view of nanometric twins $(\mathbf{b})$.

The presence of fine $\gamma^{\prime}$ precipitations do not affect the twinning inside the martensite matrix. Nanometric size martensite twins are formed with no observable interference between the martensite matrix (Figure 15). Partial overlapping of nanoparticle and twins images can be explained by the fact that they exhibit partial coherence, and therefore also overlapping diffraction reflections. 

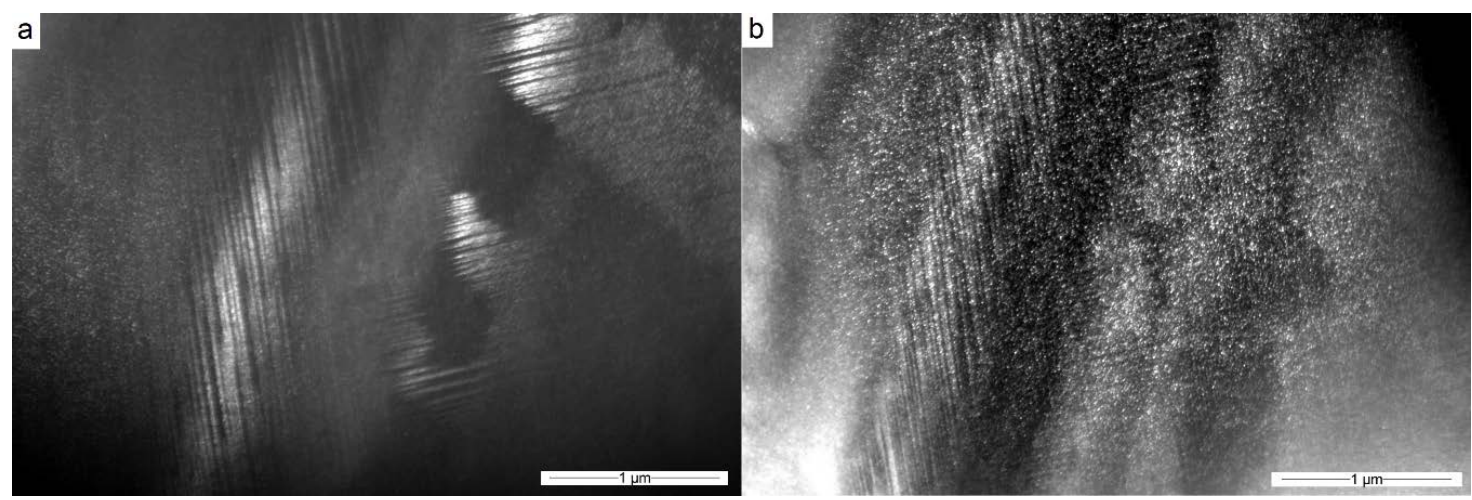

Figure 15. Dark-field TEM images of (a) the twinned martensite phase and (b) $\gamma^{\prime}$ nanoparticles at the temperature of $133 \mathrm{~K}$.

\section{Discussion}

Room temperature observations of the $\mathrm{Co}_{49} \mathrm{Ni}_{21} \mathrm{Ga}_{30}$ [001]-oriented single crystal in its quenched state by means of TEM methods allowed to observe a homogeneous, single-phase microstructure of B2 austenite with slip occurred on the $\{001\}$ plane family (Figure 2a). Room temperature observations of the $\mathrm{Co}_{49} \mathrm{Ni}_{21} \mathrm{Ga}_{30}$ [001]-oriented single crystal in its quenched and aged state did not show the presence of a tweed pattern, but most of the field of view was covered with $\gamma^{\prime}$ nanoparticles (Figure 8) of the size $12.9 \pm 2.4 \mathrm{~nm}$ (Figure 9). The presence of the $\gamma^{\prime}$ phase, sometimes misinterpreted as the $\omega$ phase, was confirmed by diffraction patterns taken in a different zone axis (Figure 8). The size and slightly elongated spherical shape of the nanoparticles correspond to assumptions based on earlier work [17].

The martensite micro modulation found in [15] was not observed. There is a possibility that the authors described "micro modulation" for the presence of fine, nanometric twinning (Figure 14). This theory has confirmation in high-resolution TEM (HRTEM) observations [15]. The authors of cited work additionally combine the presence of additional diffraction points with the presence of a special order inside the martensite structure. Observations described in the present research do not support this theory. The same paper makes the hypothesis of the presence of residual austenite in the martensitic material after quenching and ageing. The theory, however, did not receive full support in either work [25] or in the research described above.

Observations of the electron diffraction patterns of both sets of samples confirmed the presence of $\mathrm{B} 2$ to $\mathrm{L} 1_{0}$ transformations. Some of the SAED patterns of the quenched samples show the presence of similar additional diffraction spots as the spots corresponding to the presence of $\gamma^{\prime}$ coherent precipitations (Figures 2 and 4). Their presence may be caused by the appearance of particles of a size that goes beyond the observation possibilities or local ordering of the crystal lattice. The second explanation corresponds to work [48], in which the authors show the possibility of making the Co-Ni-Ga alloy with additional local ordering.

The authors of this work performed imaging of the domain structure of the Co-Ni-Ga alloy during in situ TEM heating at temperatures of 140-300 K. The magnetic domain observations by means of Fresnel TEM imaging did not show the presence of a cross-tie wall (comparable to work in [49]), but instead of Neel or Bloch domain walls. The distinction between the two possible types of domain boundaries was not possible with the available observation method. The material in the quenched state showed no major changes in the orientation of its magnetic structure at the temperatures of $140 \mathrm{~K}$ to $300 \mathrm{~K}$ (Figure 6). It showed the presence of almost parallel, elongated domains with a width of 100-200 $\mathrm{nm}$ and oriented along $\{001\}$ plane family. This agrees with literature data according to which the (100) planes of the B2 phase coincide with the direction of easy magnetization of Co-Ni-Ga single crystals [32]. This agrees with the results of previous studies, where on two sides of the thin foil two families of magnetic domains were observed, oriented towards each other at an angle of 90 * and parallel to the $\{001\}$ plane family of B2 phase [35]. At the same time, this differs from observations 
carried out on Ni-Mn-Ga alloys, where domains arranged along (110) planes were observed [31]. The material in its quenched and aged state did not show the presence of any magnetic domain wall at room temperature (Figure 10), but when lowering the temperature, it showed a growing contrast from the domain walls (Figure 11). The material in its quenched and aged state at $140 \mathrm{~K}$ presented an irregular arranged domain with a size of up to $1 \mu \mathrm{m}$ (Figures 11 and 12). Note that the in situ observation of the development of the magnetic domain structure in the shape memory material at reduced temperatures was rarely mentioned in the literature [18].

Comparison of literature [50] with the domain images contained in the practical part of the work allows the domains of material in its quenched state to be characterized as stripe domains with a minimal amount of branching, which are especially visible in Figure 3. The $\mathrm{Co}_{49} \mathrm{Ni}_{21} \mathrm{Ga}_{30}$ crystal in its quenched and aged state shows a domain structure with clearly influenced branching (Figure 12).

The domain structure of the $\mathrm{Co}_{49} \mathrm{Ni}_{21} \mathrm{Ga}_{30}$ single crystal in the [100] zone axis presents some similarities to that obtained for the magnetostrictive material during annealing with the additional influence of a magnetic field. In [50], the induced magnetic anisotropy with the easy axis perpendicular to the sample surface was produced. In the case of the author's own research, the orientation of domains was very similar, but it arose spontaneously, or under the influence of random disturbances from the environment. We hope that the observations of the domain structure development will help justify the mechanical differences between Co-Ni-Ga alloys after quenching and additional ageing [36,51].

The observations performed on high-resolution Lorentz TEM allowed us to observe fine, $12 \mathrm{~nm}$ wide, parallel magnetic domain boundaries in the quenched sample. They showed contrast many times weaker than the domain boundaries observed at conventional TEM, which may, however, depend on the defocus value not known in every microscope. One of the further research steps may therefore be the analysis of domain structure on various observational scales, from Kerr light microscopy, through low-resolution conventional TEM to state-of-the-art electron holography, MFM, or high-resolution Fresnel microscopy. It seems interesting to compare the results of the above work with an experiment carried out with the help of MFM methods [29,30], which, however, were used for in situ research [31].

Author Contributions: Conceptualization, A.M.Z.; Formal analysis, A.M.Z.; Investigation, A.M.Z.; Methodology, A.M.Z.; Software, W.D.; Supervision, W.D.; Visualization, A.M.Z.; Writing—original draft, A.M.Z.; Writing一review \& editing, A.M.Z. All authors have read and agreed to the published version of the manuscript.

Funding: This research received no external funding.

Acknowledgments: Authors would like to thank Hans J. Maier and Gregory Gerstein from Leibnitz Universität Hannover (Federal Republic of Germany) for providing the research material and consultation. The authors would also thank Yu. I. Chumlyakov from State University Tomsk (Russian Federation) for producing single crystals, Aleksandra Królicka from Wroclaw University of Science and Technology (Poland) for helping in observation using the cooling/heating Lorentz TEM method, and for JEOL EUROPE for providing access for the high-resolution microscope.

Conflicts of Interest: The authors declare no conflicts of interest.

\section{Appendix A}

Fresnel image sets for $\mathrm{Co}_{49} \mathrm{Ni}_{21} \mathrm{Ga}_{30}$ monocrystal in its quenched and aged state at various intermediate temperatures are shown in Figures A1 and A2. In addition to the appearance of the domain structure, extinction contours can be seen moving, which is of course associated with a slight change in the shape and orientation of the sample during temperature change. It is worth remembering that the observations were made during the heating of the sample, and therefore the sample had a martensitic structure up to the temperature of $293 \mathrm{~K}$. 


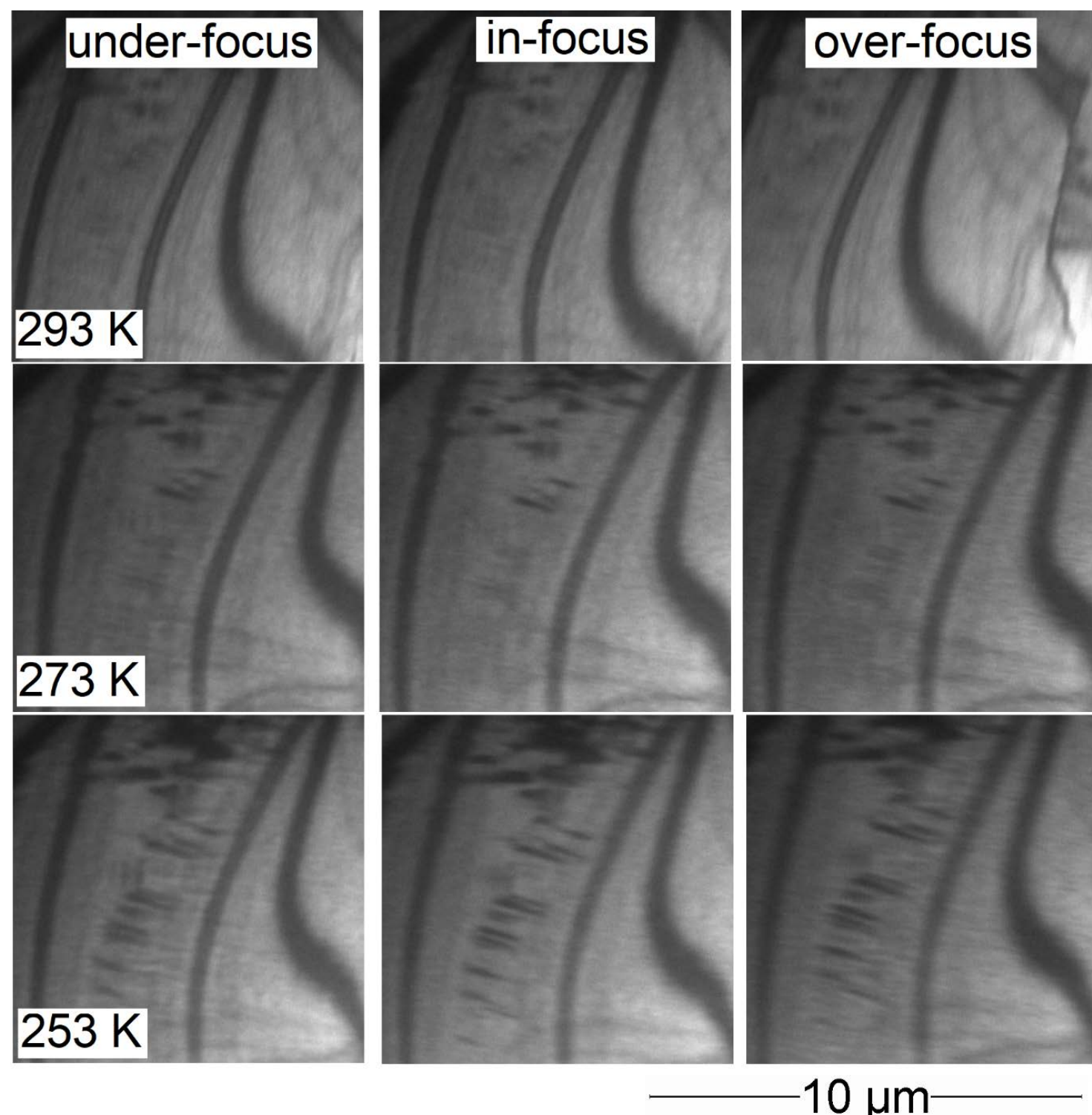

Figure A1. Development of the magnetic domain structure on Fresnel images of the $\mathrm{Co}_{49} \mathrm{Ni}_{21} \mathrm{Ga}_{30}$ monocrystal in its quenched and aged state at the temperatures of $293 \mathrm{~K}, 273 \mathrm{~K}$, and $253 \mathrm{~K}$, observed at different amounts of defocus. 

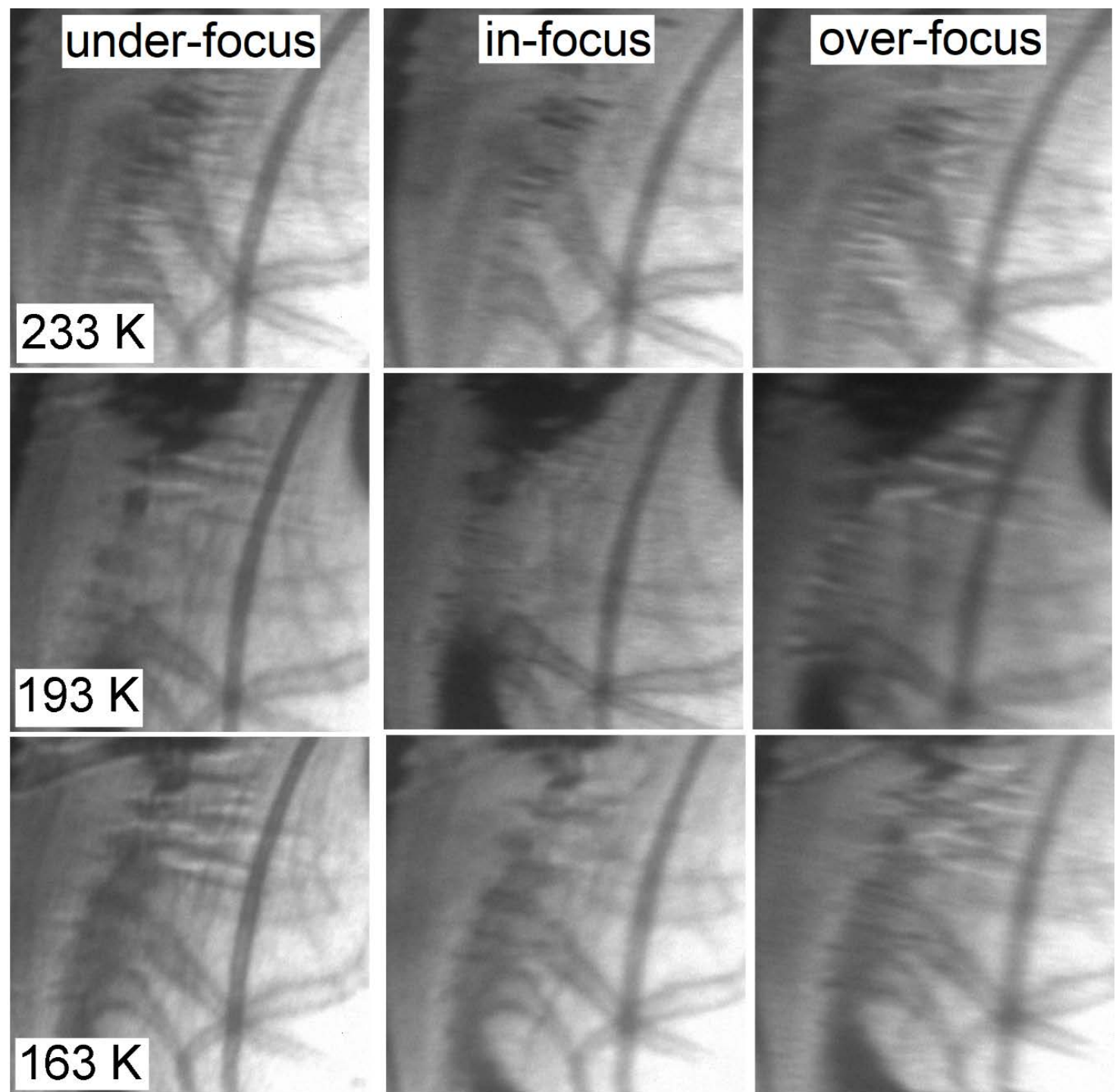

\section{$163 \mathrm{~K}$}
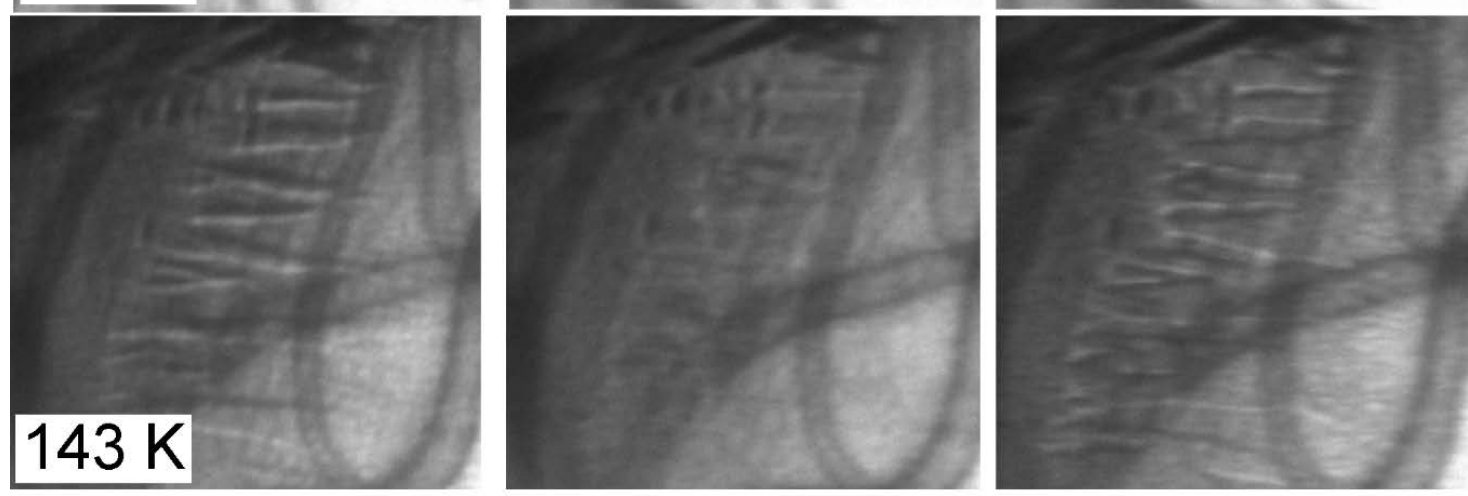

$10 \mu \mathrm{m}$

Figure A2. Development of the magnetic domain structure on Fresnel images of the $\mathrm{Co}_{49} \mathrm{Ni}_{21} \mathrm{Ga}_{30}$ monocrystal in its quenched and aged state at the temperatures of $233 \mathrm{~K}, 193 \mathrm{~K}, 163 \mathrm{~K}$, and $143 \mathrm{~K}$, observed at different amounts of defocus.

\section{References}

1. Liu, G.D.; Liu, Z.H.; Dai, X.F.; Yu, S.Y.; Chen, J.L.; Wu, G.H. Investigation on ferromagnetic shape memory alloys. Sci. Technol. Adv. Mater. 2016, 6, 772-777. [CrossRef] 
2. Hellner, E.; Laves, F. Kristallchemie des In und Ga in Legierungen mit einigen bergangselementen (Ni Pd Pt $\mathrm{Cu}$ Ag und Au). Z. Nat. A 1946, 3, 177-184. [CrossRef]

3. Cao, Z.-M.; Shi, X.; Xie, W.; Ohnuma, I.; Ishida, K.; Qiao, Z.-Y. Thermodynamic reassessment of Ni-Ga binary system. Rare Met. 2015, 34, 864-872. [CrossRef]

4. Predel, B. Co-Ni (Cobalt-Nickel). Landolt-Börnstein-Group IV Physical Chemistry. In Numerical Data and Functional Relationships in Science and Technology; Springer: Berlin/Heidelberg, Germany, 1994; Volume 5, ISBN 978-3-540-56072-2.

5. Liu, J.; Xie, H.; Huo, Y.; Zheng, H.; Li, J. Microstructure evolution in CoNiGa shape memory alloys. J. Alloy. Compd. 2006, 420, 145-157. [CrossRef]

6. Brown, P.J.; Ishida, K.; Kainuma, R.; Kanomata, T.; Neumann, K.-U.; Oikawa, K.; Ouladdiaf, B.; Ziebeck, K.R.A. Crystal structures and phase transitions in ferromagnetic shape memory alloys based on $\mathrm{Co}-\mathrm{Ni}-\mathrm{Al}$ and Co-Ni-Ga. J. Phys. Condens. Matter 2005, 17, 1301-1310. [CrossRef]

7. Chernenko, V.A.; Besseghini, S.; Villa, E.; Gambardella, A.; Pérez-Landazabal, J.I. Elastic and superelastic properties of Co49Ni22Ga29 single crystal. Appl. Phys. Lett. 2007, 90, 201914. [CrossRef]

8. Oikawa, K.; Ota, T.; Imano, Y.; Omori, T.; Kainuma, R.; Ishida, K. Phase equilibria and phase transformation of Co-Ni-Ga ferromagnetic shape memory alloy system. J. Phase Equilibria Diffus. 2006, 27, 75-82. [CrossRef]

9. Pond, R.C.; Muntifering, B.; Müllner, P. Deformation twinning in Ni2MnGa. Acta Mater. 2012, 60, 3976-3984. [CrossRef]

10. Goryczka, T.; Gigla, M.; Morawiec, H. Effect of quenching on martensitic transformation course in non-stoichiometric NiMnGa alloy. Int. J. Appl. Electromagn. Mech. 2006, 23, 81-88. [CrossRef]

11. Li, Y.; Xin, Y.; Chai, L.; Ma, Y.; Xu, H. Microstructures and shape memory characteristics of dual-phase Co-Ni-Ga high-temperature shape memory alloys. Acta Mater. 2010, 58, 3655-3663. [CrossRef]

12. Prusik, K.; Kostrubiec, B.; Goryczka, T.; Dercz, G.; Ochin, P.; Morawiec, H. Effect of composition and heat treatment on the martensitic transformations in Co-Ni-Ga alloys. Mater. Sci. Eng. A 2008, 481-482, 330-333. [CrossRef]

13. Dogan, E.; Karaman, I.; Chumlyakov, Y.I.; Luo, Z.P. Microstructure and martensitic transformation characteristics of CoNiGa high temperature shape memory alloys. Acta Mater. 2011, 59, 1168-1183. [CrossRef]

14. Fu, H.; Yu, H.J.; Teng, B.H.; Zhang, X.Y.; Zu, X.T. Magnetic properties and magnetic entropy change of Co50Ni22Ga28 alloy. J. Alloy. Compd. 2009, 474, 595-597. [CrossRef]

15. Kireeva, I.V.; Picornell, C.; Pons, J.; Kretinina, I.V.; Chumlyakov, Y.I.; Cesari, E. Effect of oriented $\gamma^{\prime}$ precipitates on shape memory effect and superelasticity in Co-Ni-Ga single crystals. Acta Mater. 2014, 68, 127-139. [CrossRef]

16. Kireeva, I.V.; Pons, J.; Picornell, C.; Chumlyakov, Y.I.; Cesari, E.; Kretinina, I.V. Influence of $\gamma^{\prime}$ nanometric particles on martensitic transformation and twinning structure of L10 martensite in Co-Ni-Ga ferromagnetic shape memory single crystals. Intermetallics 2013, 35, 60-66. [CrossRef]

17. Kuksgauzen, I.V. ТЕРМОУПРУГИЕ МАРТЕНСИТНЫЕПРЕВРАЩЕНИЯ ИФУНКЦИОНАЛЬНЫЕСВОЙСТВА В МОНОКРИСТАЛЛАХФЕРРОМАГНИТНОГОСПЛАВА

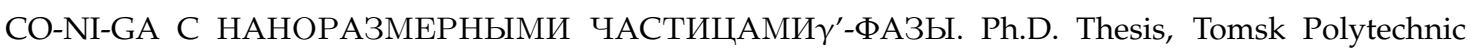
University, Tomsk, Russia, 2015.

18. Bartova, B.; Wiese, N.; Schryvers, D.; Chapman, J.N.; Ignacova, S. Microstructure of precipitates and magnetic domain structure in an annealed Co38Ni33Al29 shape memory alloy. Acta Mater. 2008, 56, 4470-4476. [CrossRef]

19. Ma, J.; Hornbuckle, B.C.; Karaman, I.; Thompson, G.B.; Luo, Z.P.; Chumlyakov, Y.I. The effect of nanoprecipitates on the superelastic properties of FeNiCoAlTa shape memory alloy single crystals. Acta Mater. 2013, 61, 3445-3455. [CrossRef]

20. Kishi, Y.; Graef, M.; Craciunescu, C.; Lograsso, T.A.; Neumann, D.A.; Wuttig, M. Microstructures and transformation behavior of CoNiGa ferromagnetic ahape memory alloys. J. Phys. IV 2003, 112, 1021-1024. [CrossRef]

21. Planes, A.; Manosa, L.; Saxena, A. Magnetism and Structure in Functional Materials; Springer: Berlin/Heidelberg, Germany, 2005; ISBN 978-3-540-23672-6.

22. de Graef, M.; Venkateswaran, S.; Kishi, Y.; Lograsso, T.A.; Viehland, D.; Wuttig, M. Magnetic Tweed Contrast In Ferromagnetic Shape Memory Alloys. Microsc. Microanal. 2003, 9, 584-585. [CrossRef] 
23. Zhang, H.R.; Ma, C.; Tian, H.F.; Wu, G.H.; Li, J.Q. Martensitic transformation of Ni2FeGa ferromagnetic shape-memory alloy studied via transmission electron microscopy and electron energy-loss spectroscopy. Phys. Rev. B 2008, 77, 301. [CrossRef]

24. Nath, H.; Phanikumar, G. Premartensite transition in Ni2FeGa Heusler alloy. Mater. Charact. 2015, 102, $24-28$. [CrossRef]

25. Neudert, A.; Lai, Y.W.; Schäfer, R.; Kustov, M.; Schultz, L.; McCord, J. Magnetic Domains and Twin Boundary Movement of NiMnGa Magnetic Shape Memory Crystals. Adv. Eng. Mater. 2012, 14, 601-613. [CrossRef]

26. Breczko, T.M.; Grechishkin, R.M.; Ilyashenko, S.E.; Nelaev, V.V.; Dovzhik, K.N.; Korpusov, O.M. Martensitic and magnetic domain structures of ferroics of the Ni-Mn-Ga and Co-Ni-Ga families. Phys. Solid State 2010, 52, 101-104. [CrossRef]

27. Lai, Y.W.; Scheerbaum, N.; Hinz, D.; Gutfleisch, O.; Schäfer, R.; Schultz, L.; McCord, J. Absence of magnetic domain wall motion during magnetic field induced twin boundary motion in bulk magnetic shape memory alloys. Appl. Phys. Lett. 2007, 90, 192504. [CrossRef]

28. Liu, J.; Li, J.G. Magnetic force microscopy observations of $\mathrm{Co}-\mathrm{Ni}-\mathrm{Ga}$ and $\mathrm{Co}-\mathrm{Ni}-\mathrm{Al}$ alloys with two-phase structures. Scr. Mater. 2006, 55, 755-758. [CrossRef]

29. Diestel, A.; Backen, A.; Neu, V.; Schultz, L.; Fähler, S. Magnetic domain structure of epitaxial Ni-Mn-Ga films. Scr. Mater. 2012, 67, 423-426. [CrossRef]

30. Diestel, A.; Neu, V.; Backen, A.; Schultz, L.; Fähler, S. Magnetic domain pattern in hierarchically twinned epitaxial Ni-Mn-Ga films. J. Phys. Condens. Matter 2013, 25, 266002. [CrossRef]

31. Pan, Q.; James, R.D. Micromagnetic study of Ni2MnGa under applied field (invited). J. Appl. Phys. 2000, 87, 4702-4706. [CrossRef]

32. Morito, H.; Oikawa, K.; Fujita, A.; Fukamichi, K.; Kainuma, R.; Ishida, K. Stress-assisted large magnetic-field-induced strain in single-variant Co-Ni-Ga ferromagnetic shape memory alloy. J. Phys. Condens. Matter 2009, 21, 256002. [CrossRef]

33. Venkateswaran, S.P.; Nuhfer, N.T.; de Graef, M. Magnetic domain memory in multiferroic Ni2MnGa. Acta Mater. 2007, 55, 5419-5427. [CrossRef]

34. Gerstein, G.; L'vov, V.A.; Żak, A.; Dudziński, W.; Maier, H.J. Direct observation of nano-dimensional internal structure of ferromagnetic domains in the ferromagnetic shape memory alloy Co-Ni-Ga. J. Magn. Magn. Mater. 2018, 466, 125-129. [CrossRef]

35. Żak, A.; Łaszcz, A.; Hasiak, M.; Gerstein, G.; Maier, H.J.; Dudziński, W. Ion polishing as a method of imaging the magnetic structures in CoNiGa monocrystal. Results Phys. 2018, 10, 277-280. [CrossRef]

36. Kuksgauzen, I.V.; Kireeva, I.V.; Chumlyakov, Y.I.; Maier, H. Shape memory effect and superelasticity in [001]-single crystal of CoNiGa aged alloy. Tambov Univ. Rep. Ser. Nat. Tech. Sci. 2016, 21, 1085-1088. [CrossRef]

37. Dadda, J. Thermomechanical and Microstructural Characterization of Co49Ni21Ga30 and Co38Ni33Al29 High-Temperature Shape Memory Alloy Single Crystals. Ph.D. Thesis, der Universit“at Paderborn, Paderborn, Germany, 2009.

38. Kireeva, I.V.; Pobedennaya, Z.V.; Chumlyakov, Y.I.; Pons, J.; Cesari, E.; Karaman, I. Effect of orientation on the high-temperature superelasticity in Co49Ni21Ga30 single crystals. Tech. Phys. Lett. 2009, 35, 186-189. [CrossRef]

39. Fuller, H.W.; Hale, M.E. Determination of Magnetization Distribution in Thin Films Using Electron Microscopy. J. Appl. Phys. 1960, 31, 238-248. [CrossRef]

40. Fuller, H.W.; Hale, M.E. Domains in Thin Magnetic Films Observed by Electron Microscopy. J. Appl. Phys. 1960, 31, 1699-1705. [CrossRef]

41. Białobrzeska, B.; Dziurka, R.; Żak, A.; Bała, P. The influence of austenitization temperature on phase transformations of supercooled austenite in low-alloy steels with high resistance to abrasion wear. Arch. Civ. Mech. Eng. 2018, 18, 413-429. [CrossRef]

42. Dmitruk, A.; Naplocha, K.; Żak, A.; Strojny-Nędza, A.; Dieringa, H.; Kainer, K.U. Development of Pore-Free Ti-Si-C MAX/Al-Si Composite Materials Manufactured by Squeeze Casting Infiltration. J. Mater. Eng Perform. 2019, 28, 6248-6257. [CrossRef]

43. Naveed, M.; Obrosov, A.; Zak, A.; Dudzinski, W.; Volinsky, A.; Weiß, S. Sputtering Power Effects on Growth and Mechanical Properties of Cr2AlC MAX Phase Coatings. Metals 2016, 6, 265. [CrossRef]

44. Hirsch, P.B. Electron Microscopy of Thin Crystals; Plenum Press: London, UK, 1967. 
45. Andrews, K.W.; Dyson, D.J.; Keown, S.R. Interpretation of Electron Diffraction Patterns; Springer Science+Business Media: Rotherkam, UK, 1967.

46. Williams, D.; Carter, C. Transmission Electron Microscopy. A Textbook for Materials Science, 2nd ed.; Springer: New York, NY, USA, 2008; ISBN 9780387765006.

47. Schneider, C.A.; Rasband, W.S.; Eliceiri, K.W. NIH Image to ImageJ: 25 years of image analysis. Nat. Methods 2012, 9, 671-675. [CrossRef]

48. Dai, X.; Liu, G.; Li, Y.; Qu, J.; Li, J.; Chen, J.; Wu, G. Structure and magnetic properties of highly ordered Co2NiGa alloys. J. Appl. Phys. 2007, 101, 09N503. [CrossRef]

49. Gentils, A.; Chapman, J.N.; Xiong, G.; Cowburn, R.P. Variation of domain-wall structures and magnetization ripple spectra in permalloy films with controlled uniaxial anisotropy. J. Appl. Phys. 2005, 98, 53905. [CrossRef]

50. Hubert, A.; Schafer, R. Magnetic Domains. The Analysis of Magnetic Microstructures; Springer: Berlin/Heidelberg, Germany, 1998; ISBN 978-3-540-64108-7.

51. Kuksgauzen, I.V.; Kireeva, I.V.; Chumlyakov, Y.I.; Maier, H. Orientation dependence of the shape memory effect and superelasticity in ferromagnetic Co $49 \mathrm{Ni} 21 \mathrm{Ga} 30$ single crystals with $\gamma^{\prime}$-phase particles. IOP Conf. Ser. Mater. Sci. Eng. 2015, 93, 12033. [CrossRef]

(C) 2020 by the authors. Licensee MDPI, Basel, Switzerland. This article is an open access article distributed under the terms and conditions of the Creative Commons Attribution (CC BY) license (http://creativecommons.org/licenses/by/4.0/). 